\title{
ENTRE REDES, TEIAS E FIOS: PENSANDO E ENSINANDO MATEMÁTICA NOS ANOS INICIAIS
}

\author{
AMONG NETWORKS, WEBS AND WIRES: THINKING AND TEACHING \\ MATHEMATICS IN THE INITIAL YEARS
}

\author{
Vanessa de Oliveira \\ Universidade Estadual Paulista / vanessadeoliveira31@yahoo.com \\ Rosa Monteiro Paulo \\ Universidade Estadual Paulista / rosamonteiropaulo@gmail.com \\ Ingrid Cordeiro Firme \\ Universidade Estadual Paulista / ingfirme@gmail.com
}

\begin{abstract}
Resumo
Vivemos em uma sociedade na qual o desenvolvimento humano, tecnológico e intelectual acontece de forma rápida exigindo mudanças e transformações inevitáveis. Mas, será que em todos os âmbitos existe essa reflexão sobre as novas demandas? No contexto escolar, em especial no ensino de matemática, ainda percebemos práticas e formas de tratar o conteúdo que fazem com que o aluno seja passivo, dependente integralmente do professor para desenvolver as tarefas que Ihes são propostas. Nosso objetivo, neste texto, é discutir algumas necessidades atuais para o ensino de matemática evidenciando o que é feito e delineando possibilidades a partir das leituras sobre Insubordinação Criativa. Para isso, nos voltamos para o discurso e as atividades desenvolvidas com professores do $4^{\circ}$ e $5^{\circ}$ ano do Ensino Fundamental, participantes de um curso de extensão oferecido em uma parceria entre a Universidade Estadual Paulista (UNESP) e a Secretaria Municipal de Educação de Guaratinguetá. Percebemos, no decorrer do trabalho com os professores, que eles reconhecem a importância de (re)pensar suas ações para atuar em sala de aula de um modo que considere as características de seus alunos e o conhecimento matemático.
\end{abstract}

Palavras-Chave: Cálculo Mental; Educação Matemática; Insubordinação Criativa.

\begin{abstract}
We live in a society in which human, technological and intellectual development happens rapidly requiring inevitable change and transformations. But is there any reflection on the new demands at all levels? In the school context, especially in mathematics teaching, we still perceive practices and ways of dealing with content that make the student passive, totally dependent on the teacher to carry out the tasks that are proposed to them. Our objective in this text is to discuss some current needs for teaching mathematics by
\end{abstract}


showing what is done, and outlining possibility from the readings on Creative Insubordination. To do so, we return to the discourse and activities developed by 4th and 5th grade Primary School teachers participating in an extension course offered in a partnership between the State University of São Paulo (UNESP) and the Guaratinguetá Municipal Department of Education. In the course of the work with the teachers, we saw that they recognize the importance of (re)thinking their actions to act in the classroom in a way that considers the characteristics of their students and the mathematical knowledge.

Keywords: Mental Calculation; Mathematical Education; Creative Insubordination.

\section{Quando o que vejo me incomoda}

Estamos diante de um cenário onde a profissão docente enfrenta novos desafios e expectativas, em uma sociedade e sistemas educacionais que impõe novas funções para que, basicamente, atinjam objetivos que se reduzem a avaliações de grande escala. Frente às cobranças cada vez maiores, o que nos move na profissão de professor? Por que mesmo diante de tanta desvalorização e poucos recursos buscamos energia para nos manter, dia após dia, na sala de aula? Não pretendemos esgotar as possibilidades que tais questionamentos exigem, mas olhar para caminhos que nos permitam pensar sobre ser professor no cenário que destacamos. Nosso objetivo neste artigo é dialogar acerca de práticas docentes que, ao ensinar matemática nos anos iniciais do Ensino Fundamental, tem como foco o desenvolvimento do aluno. O diálogo inspira-se nas leituras sobre Insubordinação Criativa ou Subversão Responsável que realizamos e da prática vivida com professores do $4^{\circ}$ e $5^{\circ}$ ano em um curso de extensão.

Ao ensinar matemática para alunos de 9 a 11 anos, esses professores tem 0 desafio de apresentar uma ciência que os ajudem a pensar e não apenas um modo de fazer que se paute na reprodução de técnicas. Segundo D Ambrósio (2015) o objetivo da educação é apoiar, incentivar e criar oportunidades para que todos atinjam o seu potencial humano. Porém, o ensino que temos hoje e as opções que fazemos limitam as oportunidades de desenvolvimento para grande parte da população. Acerca disso, o que se tem visto em pesquisas teóricas e empíricas, é um ensino com características tecnicistas, com foco na formação de alunos para um determinado tipo de mercado de trabalho, ou seja, não se vê possibilidades de desenvolvimento diante desse objetivo da escola atual.

Mas o desejo daqueles que se voltam atentivamente para a profissão docente os fazem inquietos com tal cenário e os impulsionam à busca de alternativas para a sala de aula. Professores que ensinam matemática nos 4ํ e 5o anos do Ensino Fundamental em escolas da rede municipal de ensino de Guaratinguetá, São Paulo, se disponibilizaram a pensar sobre a matemática e o modo pelo qual ela é apresentada e compreendida pelos alunos, em um curso de extensão oferecido por uma das autoras deste texto. Percebemos, no decorrer dos encontros com os professores, que eles sentiam falta de "algo" ao ensinar matemática no seu dia a dia. Há, no incômodo, um primeiro passo, pois ao se sentirem inquietos com o modo pelo qual os alunos compreendem a matemática 
ensinada por eles, os professores se colocam em movimento de (re)pensar suas práticas, vivências e conhecimentos construídos ao longo da vida e de sua trajetória profissional. Esperava-se, na proposta do curso, que o incômodo que afeta os professores os desafiassem a apresentar uma matemática humana, passível de dúvidas e incertezas aos seus alunos.

O discurso desses sujeitos revelam ações de insubordinação criativa ao planejarem suas atividades e as discutirem na sala de aula, pois, segundo D'Ambrósio e Lopes (2015), a insubordinação criativa tem como essência e (re)criação ousada e uma subversão responsável de práticas docentes a fim de promover a produção do conhecimento matemático num espaço de diálogo e respeito de modo que os frutos desse ambiente extrapolem o ambiente escolar. Os professores com os quais convivemos no curso, ao se disporem a buscar possibilidades para a sala de aula, demonstram que há certo desconforto com o contexto considerado hoje na escola. Interpretamos que ao manifestarem o incômodo, compreendem a necessidade de se (re)inventar enquanto professor, mas sem perder o que em sua profissão considera essencial, suas origens e seus valores. Não é um movimento fácil, pois entender o novo e ser criativo exige disponibilidade e dedicação. Segundo D`Ambrósio (2015), essa criatividade requer confiança, coragem e um desejo de agir, além de uma compreensão dos problemas que vive na realidade escolar.

O curso "Contar de cabeça ou com a cabeça?", oferecido em uma parceria estabelecida entre a Universidade Estadual Paulista "Júlio de Mesquita Filho" (UNESP), campus de Guaratinguetá e a Secretaria Municipal de Educação, aconteceu no segundo semestre de 2016, com encontros semanais e carga horária de 20 horas. $O$ objetivo foi desenvolver e discutir possibilidades de se tratar atividades relacionadas ao Cálculo Mental nos anos iniciais do Ensino Fundamental. Nossa intenção foi promover um espaço de diálogo entre os professores e a pesquisadora no que se refere às atividades propostas e ao ensino e aprendizagem de matemática nesse nível de escolaridade, destacando a importância de considerar os caminhos do fazer matemática. Ao estarem no curso os professores expuseram práticas, vivências de sala de aula, suas preocupações e anseios com a disciplina.

No envolvimento com as atividades propostas, compartilhando com os pares e com a pesquisadora suas dúvidas e incertezas sobre conceitos matemáticos e sendo instigados a pensar sobre os modos de resolução, os professores colocaram-se em movimento de (re)pensar a matemática e sua prática de ensinar conteúdos dessa disciplina. Ao falar sobre suas experiências os professores expõem ações que, a nosso ver, indicam inquietações e afetações em relação a aprendizagem do aluno, colocando o foco das discussões, no decorrer do curso, nas possibilidades de o aluno compreender-se produzindo conhecimento matemático.

\section{O (re)pensar enquanto um Educador Matemático}

Quando olhamos para o que é dito pelos professores participantes da pesquisa de mestrado que subsidiou a escrita deste texto, percebemos que as manifestações de insubordinação criativa se mostram principalmente por meio dos questionamentos, pois, 
antes de pensar na matemática que é ensinada ao aluno, eles analisam seu próprio modo de entendê-la, percebendo, por exemplo, uma compreensão reduzida dos conteúdos que limitam as possibilidades de ação em sala de aula. Ou seja, os professores sentem-se limitados para ensinar matemática e, ao dialogar com o outro, mostram que não alteram modos de ensinar em função da falta de conhecimento matemático. O curso abre-lhes a oportunidade de manifestarem-se, de compartilhar saberes, analisar situações, discutir matemática e esse movimento vai permitindo que interpretemos que esse professor abrese à possibilidade de se tornar outro professor, compreendendo-se professor que ensina matemática nos anos iniciais.

As ações de subversão responsável do professor, em suas atividades profissionais diárias, decorrem do desafio que lhes é apresentado em múltiplas situações para as quais não encontram respostas pré-estabelecidas. Para fazer-lhes face, têm de pôr em movimento um conhecimento profissional construído ao longo de sua carreira, que envolve elementos como origem social, política e cultural, bem como aspectos de foro pessoal e contextual. Em seu desempenho profissional, os professores precisam mobilizar não só teorias e metodologias, mas também suas concepções, seus sentimentos e seu saber-fazer (D`AMBRÓSIO; LOPES, 2015, p. 4).

As ações de subversão responsável por parte do professor colocam em questão conhecimentos e práticas que foram construídos ao longo da vida. Quando nos voltamos para o ensino de matemática um dos questionamentos que fazemos é sobre a matemática que apresentamos aos alunos. De que matemática estamos falando? Que matemática eu ensino em sala de aula? Que matemática meus alunos compreendem? De acordo com Gutiérrez (2013) estamos lidando na escola com uma matemática que é a "árbitra da verdade", ou seja, é objetiva, não deixa dúvidas e incertezas quanto a seus procedimentos, não envolve aspectos de outra natureza e, muitas vezes, é associada à graus de inteligência do indivíduo, por isso muitos escolhem cursar essa disciplina porque "a veem como 'preto no branco', envolvendo uma única resposta certa, dando a sensação de satisfação quando se chega na resposta correta eficientemente" (GUTIÉRREZ, 2013, p. 9, tradução nossa).

Mas, quando nos voltamos para o mundo em que vivemos, nos deparamos com uma realidade que é impregnada de dúvidas e incertezas, com complexidade que desafia as ciências e contradições que nos colocam cada vez mais no movimento de (re)pensar nossas ações. Estando a escola nesse mundo em que vivemos, é nela que buscamos promover um espaço onde, além de conceitos e conteúdos, é necessário promover discussões que disparem transformações. Estamos diante de uma realidade que nos exige criatividade diante de tantos obstáculos e empecilhos, exige-nos um criar, não necessariamente a partir do novo, mas que apresente alternativas e possibilidades. A matemática, se considerada nesse cenário, não pode se resumir a executar cálculos e algoritmos, a reproduzir técnicas e fórmulas, a obter respostas certas e únicas. A matemática exigida pelo mundo da complexidade em que vivemos, precisa colocar o aluno em movimento, de modo que seja possível compreender seu papel crítico dentro e fora da escola. Porém, não é isso que estamos vivenciando. 
$\mathrm{Na}$ aula de matemática não estamos lidando nem com a resolução criativa de determinados problemas, nem com o ensino de ética e valores. Ao contrário, ensinamos o mesmo currículo há 200 anos! Apesar de alterarmos constantemente o currículo de forma a remendar algo que não funciona, temos sido incapazes de fazer com que o currículo acompanhe as necessidades de formação do jovem para a sociedade moderna (D’AMBRÓSIO, 2015, p. 3).

Os professores participantes do curso de extensão, durante os encontros, expuseram alguns de seus incômodos a respeito de como a matemática é apresentada aos alunos e se dizem afetados por essa disciplina "árbitra da verdade". A disponibilidade de estar no espaço de formação continuada, não considerando tais espaços "preenchedores" de lacunas, mas oportunidade de compartilhar modos de pensar, indica que eles querem propor uma matemática diferente daquela que vivem na sala de aula. São indícios de uma subversão responsável, uma vez que "professores devem ser agentes de mudança e transformação se pretendemos investir na formação de crianças que conseguem atingir seu potencial humano máximo" (D'AMBRÓSIO, 2015, p. 3).

Questionar os modos pelos quais a matemática é entendida pela sociedade pode ser considerado os primeiros passos nas ações dos professores que visem um ensino de matemática que ajude os alunos a enfrentar os desafios da vida fora da sala de aula tornando-os capazes de pensar os problemas da sociedade não de maneira individual, mas buscando garantir os direitos de todos.

De modo geral, o que se vê no cenário escolar, é que os professores seguem regras de maneira acrítica, os gestores colocam leis e regras acima das crianças e professores, sem que se mostrem preocupações em pensar ações, atitudes e consequências. Porém, como alerta D'Ambrósio (2015) é preciso fazer-lhes "entender como [os professores] estão contribuindo para a formação de uma geração de jovens preparados e inspirados para buscar [...] um mundo melhor para todos os seres humanos" (D'AMBRÓSIO, 2015, p. 3).

Temos clareza de que a mudança exige muito mais do que vontade. Porém, para que haja mudança é preciso pensar acerca do que é possível fazer em pró da aprendizagem do aluno. Mudar não significa que se deve deixar de lado tudo que foi vivenciado para assumir uma nova postura isolada (ou divergente com) de tudo que já foi construído. Mudar, significa, sobretudo, (re)pensar prioridades, de modo que a aprendizagem do aluno seja o foco que conduz as ações da sala de aula.

Para tanto as ações de sala de aula devem ser planejadas com criticidade, conhecendo o contexto no qual estou inserido de modo que tais atitudes não alienem os alunos e sim os façam pensar a realidade e possibilidades que tem, tanto em sala de aula como fora. Esse (re)pensar ações e práticas não é uma tarefa fácil, não é descrita em nenhum documento pedagógico oficial, não são ordens a serem seguidas, é um voltar-se para o modo de ser professor e para os alunos a partir do que incomoda nas atitudes e/ou nos aspectos e condições que regem o contexto em que se está inserido. Isso implica, segundo Gutiérrez (2013), em se interessar por conhecimentos e práticas que mantenham os professores com foco no ensino para além da reprodução de fórmulas e 
técnicas, revelando uma formação matemática humana, que valorize e respeite as habilidades e limitações de cada um.

Esse desafio de (re)conhecer e buscar compreender o aluno e o contexto no qual os professores atuam é ainda maior quando o sistema educacional e os documentos pedagógicos os tratam da mesma maneira, com as mesmas características e com os mesmos objetivos a serem alcançados, onde o que importa são os resultados que esse aluno vai obter numa avaliação externa ou mesmo no mercado de trabalho. Ou seja, em todos os contextos são exigidos os mesmos métodos, as mesmas avaliações e os mesmos alunos. Mas afinal, o que nossas crianças aprendem na escola?

Partimos do pressuposto que as crianças aprendem aquilo que determinamos que elas devam aprender. Elas aprendem sobre si, quem elas são, quem elas querem ser, mas mais importante aprendem quem elas podem ou não podem ser! Elas aprendem o seu lugar na sociedade, aprendendo o seu lugar na comunidade social da sala de aula. Elas aprendem como viver sob regras e normas estabelecidas por outros. Aprendem como manterem-se silenciosos diante de injustiças ou ao observarem os maus tratos sofridos por colegas. Elas aprendem que sua voz não deve ser ouvida, nem valorizada. Elas aprendem que alguém, que não as conhece, nem seus sonhos nem aspirações, estabeleceu medidas de sucesso que determinarão o seu valor humano. Elas aprendem que seu valor humano é medido pelo seu sucesso em provas e avaliações (D'AMBRÓSIO, 2015, p. 4).

Quando nos colocamos no movimento de buscar conhecer e entender os alunos que fazem parte do nosso cotidiano já estamos desafiando o que há muito tempo não é tido como natural. Já desafiamos na medida em que entendemos que as avaliações padronizadas julgam habilidades individuais num mundo onde os problemas devem ser pensados e discutidos num coletivo maior, quando entendemos que nosso modo de ensinar e aprender se modificaram ao longo do tempo e que redefinir estratégias e métodos é necessário, pois quando eu repenso a minha profissão de formador de "números" para a sociedade, a percebo como um constante aprender que se dedica a entender e compreender os espaços públicos e ao entender o nosso cenário escolar agimos a partir e para ele.

Esse agir é carregado de intencionalidade, de objetivos e posições do professor diante de diferentes aspectos. De acordo com Gutiérrez (2013) o docente contribui com as relações que os alunos estabelecem com a matemática e como estas influenciam no entendimento das características que envolvem o espaço escolar. Percebemos que o professor deixou de ser o responsável pela transmissão de conhecimentos sendo, atualmente, necessário um comprometimento com uma educação que vise à criação de um mundo onde se possa viver uma vida com dignidade. Dessa forma os professores

precisam ser capazes de fazer mais do que apenas construir bons planos de aula que são baseados em inquéritos ou estar preparados para desenvolver relacionamentos significativos com seus alunos. 
Eles devem ser capazes de desconstruir narrativas sendo escritas sobre educação em geral (GUTIÉRREZ, 2013, p. 6, tradução nossa).

Porém, algumas questões ainda são fortes. Diante das reflexões que fazemos do contexto e aspectos vividos, o que podemos fazer? Quais as possibilidades possíveis de criar para e com os alunos? Quando pensamos nas diferentes áreas do conhecimento percebe-se que há desenvolvimento quando nos dispomos a pensar de maneira não usual, quando se busca ir além do que se conhece, explorando o novo, o diferente, ou seja "sempre que indivíduos assumem riscos e quebram regras e normas aceitas, numa tentativa de criar novos espaços para novas ideias e estratégias" (D'AMBRÓSIO, 2015, p. 6). Esses questionamentos nos remetem a importância do ser criativo frente a estereótipos enraizados na cultura e difundidos na sociedade.

No dicionário Michaelis (2017) o verbo criar pode ser entendido como dar forma, inventar ou imaginar algo novo. Entendemos que ser criativo é dar forma a caminhos ainda não trilhados, é buscar possibilidades escondidas na comodidade do dia a dia, levando sempre em consideração o contexto da experiência vivida. Assim como D'Ambrósio e Lopes (2015), acreditamos que a criatividade humana precisa ser direcionada e movida para ações positivas e em prol do bem-estar humano, de modo que nos estejamos sempre comprometidos com o respeito ao outro.

É nesse movimento onde os professores se sentem incomodados com as políticas educacionais e com suas próprias práticas, que destacamos a importância do ser criativo, e mais, a relevância de estabelecer ações de insubordinação criativa ou de subversão responsável em que o foco seja outro, volte-se para o aluno. De acordo com D'Ambrósio e Lopes (2015) as ações que se distinguem do comum, do trivial, e do não pensado, decorrem dos múltiplos desafios que os professores enfrentam diariamente e muitas vezes não encontram respostas imediatas. Para que haja segurança é necessário mobilizar conhecimentos que foram construídos ao longo da vida, porém com uma mudança de atitude, em que os docentes não lidem apenas com conhecimentos teóricos e metodológicos, mas também analisem suas concepções, seus sentimentos e seu saberfazer de forma que isso os faça perceber o que conhece e o que tem possibilidade de vir a conhecer.

As inquietações e afetações dos professores no cenário que atuam são fundamentais para as primeiras mobilizações. Muitos, porém, mesmo lidando com dilemas, ainda se colocam numa posição tímida. A mudança exige, em primeiro lugar, que o professor procure conhecer e pensar a sua própria realidade, buscando nos sistemas, nos currículos e na gestão escolar oportunidade de diálogo que possibilitem a formação de alunos críticos e responsáveis.

Consideramos que essa tarefa de formar envolve ações políticas nas quais o professor precisa conhecer e interpretar regras de modo a desconstruir conceitos prévios acerca do mundo em que vive e da disciplina que ensina, em nosso caso, a matemática. Criar oportunidades para fazer matemática valorizando e respeitando os alunos, antes de classificá-los de acordo com os resultados que obtém, são os primeiros passos. Vale ressaltar que não se trata de opor-se e "driblar" normas e regras, mas de voltar-se para o tido como natural, como normal, como "certo", com um olhar cuidadoso, crítico e focado 
na aprendizagem do aluno. Esse olhar possibilita ver, até mesmo dentro de normas e regras, oportunidades para a insubordinação criativa ou a subversão responsável que descrevem D'Ambrosio e Lopes (2015).

$\mathrm{Na}$ convivência com os professores que conosco estiveram no decorrer do curso que discutimos neste texto, vimos, em seu modo de dizer, em suas ações, em seus gestos e fisionomias, atitudes que os dispõem a ser insubordinados criativamente. Professores que se mostraram dispostos a (trans)formar práticas de ensinar matemática para valorizar o feito pelo aluno, o discutindo. Na sequência deste artigo passamos a trazer mais alguns elementos que permitam ver esse movimento com os professores que nos arriscamos a chamar de atitudes insubordinadas ou modos de não se satisfazer com o que é dado, olhando para potencialidades da (trans)formação.

\section{O Contexto da Experiência Vivida}

Conforme dissemos, no curso, houve atividades planejadas que serviram de abertura ao pensar. Elas foram criadas a partir da inspiração do que nos dizem documentos oficiais como os Parâmetros Curriculares Nacionais (1997) e as Orientações Curriculares do Estado de São Paulo - Matemática (2014). Também nos voltamos para pesquisas que abordam o sentido do Cálculo Mental de modo a compreender a sua potencialidade para o ensinar e aprender matemática nos anos iniciais. Focamos alguns conteúdos curriculares como operações elementares (adição, subtração, multiplicação e divisão), a estimativa e aproximações. Propusemos ações que envolviam, por exemplo, situações problemas e o uso da calculadora. $O$ trabalho com os professores foi desenvolvido em grupo de 4 a 5 participantes de modo que fosse possível o diálogo e a troca de informações. A dinâmica envolvia dois momentos: o pensar nos grupos e a exposição coletiva que abria as possibilidades antevistas para a sala de aula. Os encontros foram filmados de modo que fosse possível registrar a expressão dos professores e, mediante análise posterior, ver o modo pelo qual eles compreendiam o Cálculo Mental.

Os professores que participaram do curso têm características bastante comuns às da classe, eles se dividem em diferentes escolas situadas em municípios distintos, alguns possuem recursos escassos para trabalhar, outros precisam lidar com uma gestão e equipe escolar que os questionam negativamente quando assumem atitudes que fogem do convencional, mas a característica comum a todos e que nos chama a atenção é que, mesmo com as dificuldades encontradas, todos estavam dispostos a pensar e discutir como a matemática é apresentada aos alunos.

É importante que a palavra aluno receba destaque, pois ela permeou todos os encontros. Sempre os professores questionavam como as atividades propostas no curso poderiam ser desenvolvidas na sala de aula, destacando os aspectos positivos e negativos que percebiam. Vimos que eles estavam naquele espaço por diferentes motivos, mas todos tinham algo comum: a preocupação com o aluno.

Para compreender os motivos que levou cada um ao curso, a seguir trazemos algumas de suas respostas. Esclarecemos que neste texto, como na pesquisa, os nomes são fictícios para preservar a identidade dos professores. 
Amanda: "Minha busca sempre é por meios de fazer com que os alunos compreendam e saibam utilizar a matemática na vida, por encontrar diferentes estratégias para que aprendam os conteúdos da proposta curricular e tenham prazer em trabalhar com a matemática".

Eva: "Percebe-se que nossos alunos estão 'desanimados' em desenvolver atividades sistemáticas dentre todas as áreas de ensino. Portanto buscar inovações, novas ferramentas que nos garanta uma aproximação com o corpo discente. Temos que sempre buscar novas maneiras de apresentar a matemática"

Mônica: "Tornar o ensino de matemática em aulas prazerosas, motivadoras, e desafiadoras para os alunos e até para mim mesmo "

$\mathrm{Na}$ fala das 3 professoras vê-se que há uma preocupação com a forma que a matemática é ensinada para o aluno. A professora Amanda faz um destaque para a proposta curricular, indicando uma característica de subversão responsável se consideramos que ela não tem como objetivo opor-se aos documentos oficiais, mas buscar meios que lhe permitam trabalhar criativamente a partir do que lhe é proposto. D'Ambrósio e Lopes (2015) destacam que, em alguns momentos, nós professores acabamos assumindo práticas impostas por especialistas que estão à margem de nossos contextos. Quando as falas das professoras destacam a busca por novas estratégias, novas ferramentas, aulas prazerosas e motivadoras vê-se manifestar o cuidado com os alunos, as preocupações em colocá-los também como responsáveis por sua aprendizagem, uma aprendizagem que vá além de atividades sistematizadas.

Mas, como pensar em atividades que não envolvam apenas cálculos mecanizados e algoritmo como resposta? Como compreender uma matemática que vá além do certo ou errado? Que não se limite a um conhecimento sistematizado e que possa estar presente em nossas ações diárias? Na escola, a matemática, uma ciência exata, faz jus ao nome e nos é apresentada de maneira hierarquizada. Essa "organização" faz com que tanto professores quanto alunos sintam-se "acorrentados" diante de uma rigidez que dificulta encontrar aberturas para entendê-la como algo presente em nossa experiência de vida.

Buscamos, no decorrer do curso, despertar no professor a curiosidade por esse tipo de atividade dando liberdade e incentivando os integrantes do grupo a considerarem alternativas para a resolução (e resposta) das situações que lhes eram propostas. A princípio, essa não foi uma tarefa fácil, pois os mesmos estavam "presos" ao que conheciam. Porém, consideramos com Vasconcelos (2013) que para agir de maneira diferente é necessário estar disposto, talvez a partir da observação de outras pessoas ou, possivelmente, a partir da leitura ou da discussão com outros colegas. Isso foi o que nos dispusemos a fazer.

Para que seja possível compreender o modo pelo qual procuramos mobilizar os professores à discussão, trazemos uma proposta de atividade. Destacamos que não se trata de abandonar o que é feito e necessariamente substituir por novas estratégias ou metodologias uma prática que vem sendo construída ao longo da constituição da profissão. No entanto, entendemos que é necessário dar oportunidade ao professor de ter outros olhares para o que vem sendo feito, levando-o a assumir uma postura crítica diante do que vem sendo feito e analisar possibilidades diversas. 


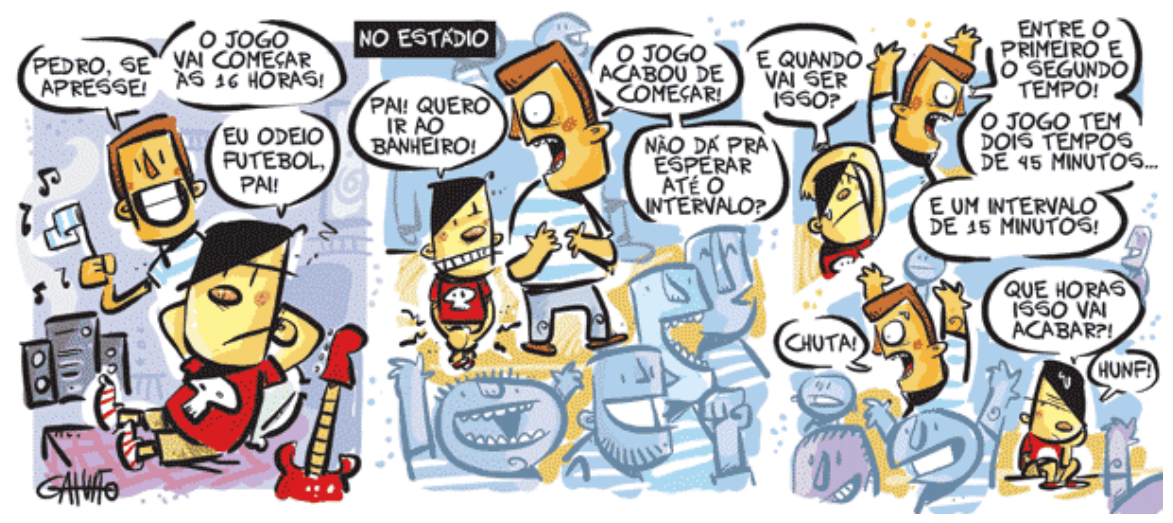

Figura 1: Charge para discussão no curso

Fonte: FRANK (2009)

Após a leitura da charge que foi projetada para o grupo, incentivamos os professores a pensarem na atividade. Os participantes viram duas possibilidades de interpretação a partir do que na charge era exposto: será que o momento em que o pai de Pedro irá levá-lo ao banheiro é no intervalo do jogo ou na hora que o jogo terminar? A professora Maria arrisca uma possibilidade de solução: "Somaria o tempo, entre o intervalo e os dois tempos, veria a hora, e calcularia o término" já a professora Deise sugere: "Pegar 16 com 45, 16:45, mais os 15 de intervalo, 17, mais os 45 do segundo tempo 17:45".

$\mathrm{Na}$ abertura à discussão os professores concordaram com as soluções apresentadas pelas colegas. Porém, o professor Lúcio expôs outra possibilidade: "Começou 16, com 45, 16:45...". A professora Manu o interrompe e intervém dizendo que sua solução não está correta. Para tanto ela argumenta que, para solucionar o problema, deve-se pensar quanto falta para o jogo terminar. Abre-se o debate.

O diálogo entre os professores leva-os a conclusão de que algumas atividades não possuem respostas imediatas ou que podem ser obtidas com a aplicação de algum algoritmo, mas após uma análise podem gerar debates em sala de aula levando à busca e permitindo que os alunos compreendam uma matemática de possibilidades. Essas situações de caráter problemático, segundo Vasconcelos (2013), favorecem a criação de ambientes de aprendizagem ricos e estimulantes, levando a diferentes soluções e, mais do que isso, a um processo de argumentação em defesa da proposta construída.

Com opiniões distintas sobre como solucionar o problema sugerido pela charge os professores iniciam o debate e a argumentação.

Manu: "Ele quer saber que horas ISSO vai acabar."

Silvana: "Não, ele quer ir ao banheiro e o pai falou que vai esperar o intervalo e quando vai ser isso [o jogo]? Aí ele respondeu pra isso, pelo menos foi o que eu entendi!"

Lúcio: "Eu entendi isso também"

Deise: "Eu entendi final do jogo" 
Fica claro que há, no diálogo, uma concepção de matemática que subsidia o raciocínio: há um "certo e errado". Segundo Skovsmose (2008), esse modo de agir e dizer do professor é pautado em uma tradição matemática escolar, na qual exercícios devem ter uma e somente uma resposta certa. O absolutismo impera na sala de aula. E, também, no discurso do docente. A maioria dos professores precisa encontrar uma única solução e, para muitos é difícil ver o aluno resolver um determinado exercício de uma maneira distinta da que ele vê ou é difícil aceitar que há um duplo sentido em uma questão que passamos tanto tempo planejando para uma determinada aula. Esse modo de pensar imperante, vigente é fruto da tradição escolar.

E como criar fendas nessa tradição? E se uma situação escapar do controle? Como dizer para o aluno que duas respostas diferentes estão certas na aula de matemática? Qual (ou quais) posicionamento assumir em sala de aula? Essas foram algumas questões que levantamos no curso para os professores quando eles se depararam com respostas diferentes para uma mesma situação. Os participantes se voltaram para a atividade e discutiram mais uma vez as estratégias de cada um. Iniciouse um movimento de ir e vir no qual se procurava não mais a solução, mas sua compreensão. Havia uma mobilização de conhecimentos e habilidades distintas para justificar as respostas. Chegou-se a algum consenso? Sobre a resposta não, mas algumas sugestões foram bastante significativas.

Silvana: "Aqui a gente tem que aceitar as duas respostas"

Maria: "Porque vai da interpretação do aluno"

Silvana: "Aqui dá pra gente entender como o aluno se sente quando a gente fala: você errou!"

Olívia: "Porque a gente vai com um pensamento [expressa-se com as mãos imitando uma caixa] e nem abre para outros"

Maria: "A gente não olha para o que ele [aluno] analisou"

Os professores reconhecem que em muitas situações não consideram os caminhos escolhidos pelos alunos e, pela análise do problema, se colocam em um movimento de (re)pensar sua prática, evidenciando análise crítica da postura em sala de aula. No discurso deles percebemos um voltar-se para o seu modo de ser professor, para o que é feito permitindo abrir-se às escolhas. Ficou clara, entre os professores, a relevância da mediação, talvez a principal tarefa do professor. Pelo questionamento na sala de aula, ao experimentar uma realidade diferente da que estamos habituados, ouvir as soluções sugeridas pelos alunos e encaminhar as propostas de modo que eles possam explicar 0 pensar, vai revelando aspectos do conhecimento matemático. A ambiguidade gerada pela interpretação do texto e as formas de solução abrem possibilidades de se fazer matemática na sala de aula que não visa algoritmos, mas valoriza o sentido (neste caso de interpretação).

Percebe-se que, pela mediação, vai se mostrando o papel do professor que é aquele que deve permitir que os alunos se expressem, sem julgar o certo ou o errado, mas compreendendo o seu raciocínio e encaminhando-o para a análise do que faz. Ou seja, a tarefa do professor numa postura aberta à aprendizagem é bem mais difícil, pois já 
não se trata de expor conteúdos, fórmulas e estratégias de resolução de exercícios. Tratase de permitir que aquele que faz, que sugere, que interpreta, analise o feito e tenha condições de reconhecer a correção do que faz. De acordo com Gutiérrez (2013) os alunos não estão acostumados com uma matemática que não seja objetiva e tenha resposta única e, desse modo, criar uma cultura em sala que possibilite tal discussão (e aceitação) também é um desafio ao professor. A fala da professora Eva mostra sua preocupação nesse sentido.

Eva: "O aluno do $5^{\circ}$ ano, que é o que a gente trabalha, [tem] essa visão de separação da matemática, como se fosse uma outra coisa, é um erro que nós professores, desde os pequenininhos, fazemos. É uma coisa de sistema educacional que separou isso, por isso que hoje a gente trabalha interligado, porque realmente eles não conseguem perceber, pra eles a matemática é uma coisa assim, é algo puramente exato, e eles não conseguem transferir isso, não que não seja exato, pro dia a dia deles. Aí quando você começa a mostrar pra eles que quando eles vão comprar um pão, tomar um refrigerante que isso tá incluso a matemática eles começam a ficar...[faz cara de surpresa]. É uma coisa que a gente tem que começar a trabalhar com eles, porque é uma coisa que tá enraizado na gente."

A fala da professora mostra que o próprio professor sente a necessidade de (re)pensar a matemática que ele ensina. Uma das alternativas destacadas pelos participantes foram as situações problemas que envolvem aspectos da rotina dos alunos. As atividades que apresentavam contextos próximos aos fatos da vida cotidiana foram as que dispararam mais discussões entre eles. Muitos argumentaram acerca da importância da experiência vivida ao ensinar matemática nos anos iniciais. A professora Sandra, por exemplo, relatou, em um dos encontros, que tinha uma aluna que ajudava os pais nos finais de semana na feira e no momento de apresentação do Sistema Monetário a aluna a auxiliava a exemplificar situações vividas por ela para os colegas. D'Ambrósio (2015) destaca que essa participação no mundo e na vida pode gerar resultados diferentes daqueles da escola. Acreditamos que essa participação pode ser potencializada positivamente quando, nos espaços escolares, os alunos integram esses conhecimentos e habilidades desenvolvendo-se como cidadãos críticos e responsáveis.

Os professores nos mostram um cenário do ensino de matemática comum nos dias atuais. O que, para nós, se destaca, são os modos pelos quais esses professores lidam com o que é natural há muito tempo. Eles reconhecem que apresentam, na maioria das vezes, uma matemática inacessível a muitos, que gera dúvidas até para eles mesmos. Ao mesmo tempo, fazem uma autocrítica e se disponibilizam, ao estar no curso, a colocar seus conhecimentos e práticas em discussão. Envolvendo-se na resolução das atividades matemáticas que Ihes eram propostas, vão (des)construindo uma imagem da matemática do certo e errado. Consideramos que as ações de insubordinação criativa são vividas por esses professores, não como proposta do curso, mas como necessidade que a eles se impõe para enfrentar o que lhe é estranho, com a intenção de melhorar as possibilidades de aprendizagem do seu aluno. 


\section{Vale considerar}

"Entre as maravilhas que descobriu em Berkeley, encontrava-se uma expressão que viu repetidas vezes e que entendeu ser uma bela e saudável metáfora. A expressão era 'a solução dos meus problemas' - que ele entendeu como uma grande quantidade de líquido, borbulhante e fumegante contendo todos os seus problemas em processo de dissolução, ou em forma de precipitação, com catalisadores dissolvendo constantemente alguns problemas (do momento) e precipitando outros. Ele ficou absolutamente desiludido ao descobrir que os residentes de Berkeley não tinham em mente esse tipo de metáfora química" (LAKOFF; JOHNSON, 2002, p. 240).

Essa seção em um texto é, na maioria das vezes, destinada às conclusões ou considerações finais sobre o exposto. Isso porque o fim da escrita do texto exige uma retomada, um voltar-se sobre o feito de modo que seja possível ver se o dito é claro a quem lê, se as ideias inicialmente consideradas relevantes para serem expostas estão explicitadas, se o objetivo foi atingido, se a metodologia está clara.

Neste texto, ao pensarmos nesse (re)ver o escrito, nos voltamos para o discurso dos professores que foram desencadeadores do desejo de querer escrever. Eles são o que, especialmente, nos provocam à escrita. Dentre as muitas falas, gestos, fisionomias, alguns foram eleitos. A eleição não é aleatória, ela tem um propósito: destacar o que foi feito revelando compreensões acerca do fazer matemática.

A cada história de vida o espaço do curso é preenchido com dúvidas e discussões que, aos poucos, dão lugar às possibilidades. As práticas de cada professor vão se tornando marcas numa trajetória em construção. A experiência vivida por eles e a busca por espaços que possam gerar diálogo traz segurança.

Como na epígrafe de Lakoff e Johnson (2002), que acima destacamos, neste momento do texto, mais do que fazer considerações finais, rever o escrito e buscar sintetizar o dito, queremos pensar o modo pelo qual a tonalidade da experiência vivida permeia o discurso construído. O que fez sentido para nós nesse modo de estar junto com o professor foi a compreensão da "solução dos meus problemas". Ela, inicialmente, revelava o desejo dos professores em ter, a moda de uma solução química, algo que diluísse tudo que eles não davam conta de resolver. No modo de estar junto uns com os outros fazendo matemática e conversando sobre modos de fazer matemática esse desejo foi sendo transformado. O curso tornou-se um espaço de cumplicidade, de aprendizagem, e essa "solução química" mostrou-se possível. Não porque ela iria diluir os problemas, mas porque nos fez (a todos nós) vê-los e enfrentá-los.

Essa é, para nós, a insubordinação mais criativa que há: pensar-se sendo professor que ensina matemática nos anos iniciais capaz de aprender matemática para ensinar. Pensar-se um ser em potencial. Pensar-se uma pessoa que, sendo capaz de ensinar, aprende. Pensar-se sendo, portanto, em movimento, nunca um ser, entendido como algo pronto, acabado, completo. Mas sendo, num espaço e tempo que é compartilhado, que é movediço, que se enriquece a medida que a "solução" vai borbulhando e é soprada por muitas forças, em especial, pela minha força que determina a direção. 


\section{Referências}

BRASIL. Parâmetros curriculares nacionais: Matemática / Secretaria de Educação Fundamental. - Brasília: SEC/SEF, 1997.

CRIAR. In: Michaelis Dicionário Brasileiro da Língua Portuguesa. Editora Melhoramentos, 2017.

Disponível em<:http://michaelis.uol.com.br/busca? $r=0 \& f=0 \& t=0 \&$ palavra=criar $>$. Acesso em: 09 ago. 2017.

D'AMBROSIO, B. S. A subversão responsável na constituição do educador matemático. In: Encuentro Colombiano de Matemática Educativa, 16., 2015, Bogotá. Memorias del Encuentro Colombiano de Matemática Educativa... Bogotá, 2015, p. 1- 8.

D'AMBRÓSIO, B. S.; LOPES, C. E. Insubordinação Criativa: um convite à reinvenção do educador matemático. BOLEMA. Boletim de Educação Matemática, Rio Claro, v. 29, n.51, p. 1-17, abr. 2015.

FRANK, M. Problemas com cálculo de tempo. 2009. Disponível em:<https://novaescola.org.br/conteudo/961/problemas-com-calculo-de-tempo>. Acesso em: 09. ago. 2017.

GUTIÉRREZ, R. Why (Urban) Mathematics Teachers Need Political Knowledge. Journal of Urban Mathematics Education, v.6, n. 2, p. 7-19, dez. 2013.

LAKOFF, G.; JOHNSON, M. Metáforas da vida cotidiana. Tradução do Grupo de Estudos da Indeterminação e da Metáfora (sob a coordenação de Maria Sophia Zanotto e Vera Maluf). Campinas: Mercado de Letras, 2002.

SÃO PAULO. Orientações Curriculares do Estado de São Paulo Anos Iniciais do Ensino Fundamental Matemática (versão preliminar): Coordenadoria de Gestão da Educação Básica CGEB. São Paulo: Secretaria da Educação, 2014. Disponível em:< http://www.educacao.sp.gov.br/a2sitebox/arquivos/documentos/962.pdf>. Acesso em 18 jul. 2015.

SKOVSMOSE, O. Desafios da reflexão em educação matemática crítica. Campinas, SP: Papirus, 2008.

VASCONCELOS, C. C. Ensino-Aprendizagem da Matemática: Velhos problemas, Novos desafios. 2015, 28 p. Notas de Aula.

Submissão: 27/08/2017

Aceite: 15/11/2017 